\title{
Analysis of the situation of Bovine Cystic Echinococcosis at the Port-Bouët Abattoir: a retrospective study from 2008-2015
}

\author{
Genevieve Lydie Yao ACAPOVI ${ }^{1}$, Jean Michel Vianney BEUGRÉ ${ }^{1}$, \\ Cyprien Bokpe YAPI ${ }^{1,2}$ and Silas Lendzele SEVIDZEM ${ }^{3,4^{*}}$ \\ ${ }^{1}$ Université Félix Houphouët Boigny, Laboratoire de Zoologie, 22 BP 582 Abidjan 22, Côte-d'Ivoire. \\ ${ }^{2}$ Laboratoire National d'Appui au Développement Agricole-Laboratoire Central Vétérinaire de Bingerville; \\ BP 206 Bingerville. \\ ${ }^{3}$ Ecole Doctorale des Grandes Ecoles (EDGE), Laboratoire d'Ecologie Vectorielle (LEV-IRET), BP: 13354, \\ Libreville, Gabon. \\ ${ }^{4}$ Programme Onchocercose Field Station of the University of Tübingen, Ngaoundéré, Cameroon. \\ *Corresponding author; E-mail: sevidzem.lendze@gmail.com; Tel:000237656420010
}

\begin{abstract}
Echinococcosis is an important zoonotic parasitic disease in Côte d'Ivoire and information on its occurrence at the Port-bouët abattoir is not yet documented. A retrospective study was carried out at the PortBouët abattoir from 2008-2015. A para-clinical examination of the isolated bovine organs (liver, kidneys, heart, lungs, tongues and spleen) for the presence of Echinococcus was carried out. There was a statistically significant difference with cases signaled per year with $2008(10.55 \%)$ and $2015(11.02 \%)$ recording the highest number of cases. Positive cases were only recovered from the kidneys. The present study provides baseline information about the echinococcosis situation at the abattoir-level and pave the way for future studies as well as in the implementation of control programs for this zoonosis in the South of Côte d'Ivoire.
\end{abstract}

(C) 2019 International Formulae Group. All rights reserved

Keywords: Echinococcosis, zoonosis, organs, bovine, Port-Bouët.

\section{INTRODUCTION}

Cystic echinococcosis (CE) or hydatidosis is an infection with Taeniidae (flatworms) of the genus Echinococcus, a tiny tapeworm which is just a few millimeters long. Five species of Echinococcus have been identified, infesting a wide range of domestic and wild animals. $\mathrm{CE}$ is a zoonotic disease with a life cycle involving two mammalian hosts. The definitive host is a carnivore like a dog where the adult worm can be found in the small intestine. Most herbivorous/omnivorous mammals and all livestock may serve as intermediate hosts (humans may be accidentally infected) in whose organs the worm forms cysts. This condition is called zoonosis which is defined as diseases and/or infections naturally transmitted from animals (vertebrates) to humans and vice versa (Savey and Dufour, 2004). Infection of a healthy host is by direct or indirect ingestion of Echinococcus eggs through contact with parasitized hosts (Marisk et al., 2008) and by ingestion of food and water contaminated with Echinococcus eggs or soil contaminated with eggs in the feces of the definitive hosts 
(Honsset et al., 2004). Thus, interactions between pathogens, hosts and the environment play an important role in the dynamics of zoonosis that could affect the health of human population especially those of animals which serve as sources of protein (Marisk et al., 2008). Indeed, animals are likely to be exposed to several zoonoses including echinococcosis (Bizuwork et al., 2012; Yang et al., 2005). This zoonosis is one of the human diseases known since antiquity (Ehsan et al., 2017).

Hippocrates (4th century BC), the father of medicine was the first to describe the occurrence of the cyst of this worm in the abdominal cavity of his patients. At that time, cysts were used to predict good and bad omen when screening the entrails of sacrificed animals (Battelli et al., 2002). Later, thanks to studies conducted by Galen ( $2^{\text {nd }}$ century BC), a great similarity was established between human cysts and those found in cattle (Ehsan et al., 2017). Echinococcosis is one of the most important helminthic diseases. Also, their impact on human and animal health on a global scale is very difficult to quantify. In many endemic countries like Côte d'Ivoire, some practices related to animal husbandry, trade and slaughter tend to favor their spread (WHO, 2006). In Africa, echinococcosis is a public health problem, particularly in most Maghreb countries such as Algeria, Morocco and Tunisia (Majorowski et al., 2005), East Africa (Kenya, Ethiopia, Sudan, etc.) and South Africa (Eckert et al., 2001). In West Africa, particularly in Ivory Coast, this zoonosis is still poorly understood (Bizuwork et al., 2012). In addition, it could be described as a "neglected disease" as very little information is available on this topic. However, cases signaled from isolated organs of cattle inspected in abattoirs often mention the presence of Echinococcus cysts in the kidneys of this intermediate host. The above observations prompted us to make an analysis of the situation of echinococcosis by considering retrospective data collected on the various cases of organ-isolates at the abattoir of Port-Bouët from 2008 to 2015.

\section{MATERIALS AND METHODS Study area}

This study was conducted in the city of Port-Bouët located in the southern part of the city of Abidjan (Côte d'Ivoire), between the Atlantic Ocean in the south and the Ebrié lagoon in the north. This municipality covers an area of $1111 \mathrm{~km}^{2}$ (Figure 1). The climate of the city of Abidjan is a sub-equatorial type, hot and humid, characterized by two rainy seasons (September to October and April to July) interspersed by two dry seasons (July to August and November to March). The temperature oscillates between 25 and $33{ }^{\circ} \mathrm{C}$ with a heavy rainfall of more than $1500 \mathrm{~mm}$ of rain per year. In recent years, there has been a disturbance in the rain patterns and consequently seasons, following the global warming of the earth (Yao-Acapovi et al., 2017). The Port-Bouët abattoir is the biggest slaughterhouse in Abidjan covering an area of more than six hectares and slaughters the highest number of animals and the main supplier of meat to the city of Abidjan.

\section{Animal sampling}

Most of the animals brought to the Port-Bouët abattoir originated from different neighboring countries, mainly Burkina Faso and Mali. Also, some other groups originated from Niger, Chad and Liberia. The study animals consisted of Bos taurus Linnaeus, 1758 cattle breed, slaughtered at the Portbouët abattoir. Data was collected by the veterinary inspection service of this slaughter house over a period of eight years, that is from 2008 to 2015. Data was collected from the annual surveillance reports of all the cattle slaughtered at the slaughterhouse of PortBouët from 2008 to 2015. The animals slaughtered during this period were counted and grouped according to the year of slaughter in order to have a more precise idea on the annual occurrence of cases. In addition, all the data relating to the various organs inspected (tongue, liver, lung, heart, kidneys and spleen) was documented in order to follow-up their variation over the years and to deduce the total number of infected organs. Furthermore, echinococcosis infected organs were grouped 
according to their state. This clinical examination made it possible to determine which of the organs was most affected by this parasitosis. Inspection of the isolated organs, likely to harbor the parasite was carried out through a thorough parasitological and clinical examination of the viscera based on the existence of macroscopic lesions that indicates echinococcosis and this was performed by a veterinarian after cattle slaughter. Target organs including the liver, lungs, spleen, kidneys and heart were recovered and were palpated and/or incised for the presence of nodules or cysts. This examination was done with a torch to improve brightness and visibility.

\section{Statistical analysis}

Data collected was computed into MS

EXCEL spreadsheet of version 2007.
Prevalence was calculated using the following formula:

Prevalence (\%)

$=\frac{\text { Number of echinococcosis cases }}{\text { Total number of animals slaughtered }}$
$\times 100$

Comparison of the prevalence according to the number of damaged organs and years of follow-up was carried out using the ANOVA test with the hypotheses: $\mathrm{HO}=$ identical prevalence during years of detection of cases and $\mathrm{H} 1=$ different prevalence according to years with cases. The Statistica (version 20.0) statistical software was used for data analysis. The level of significance was stated at $5 \%$. The results were estimated with a $95 \%$ confidence interval $[95 \% \mathrm{CI}]$.

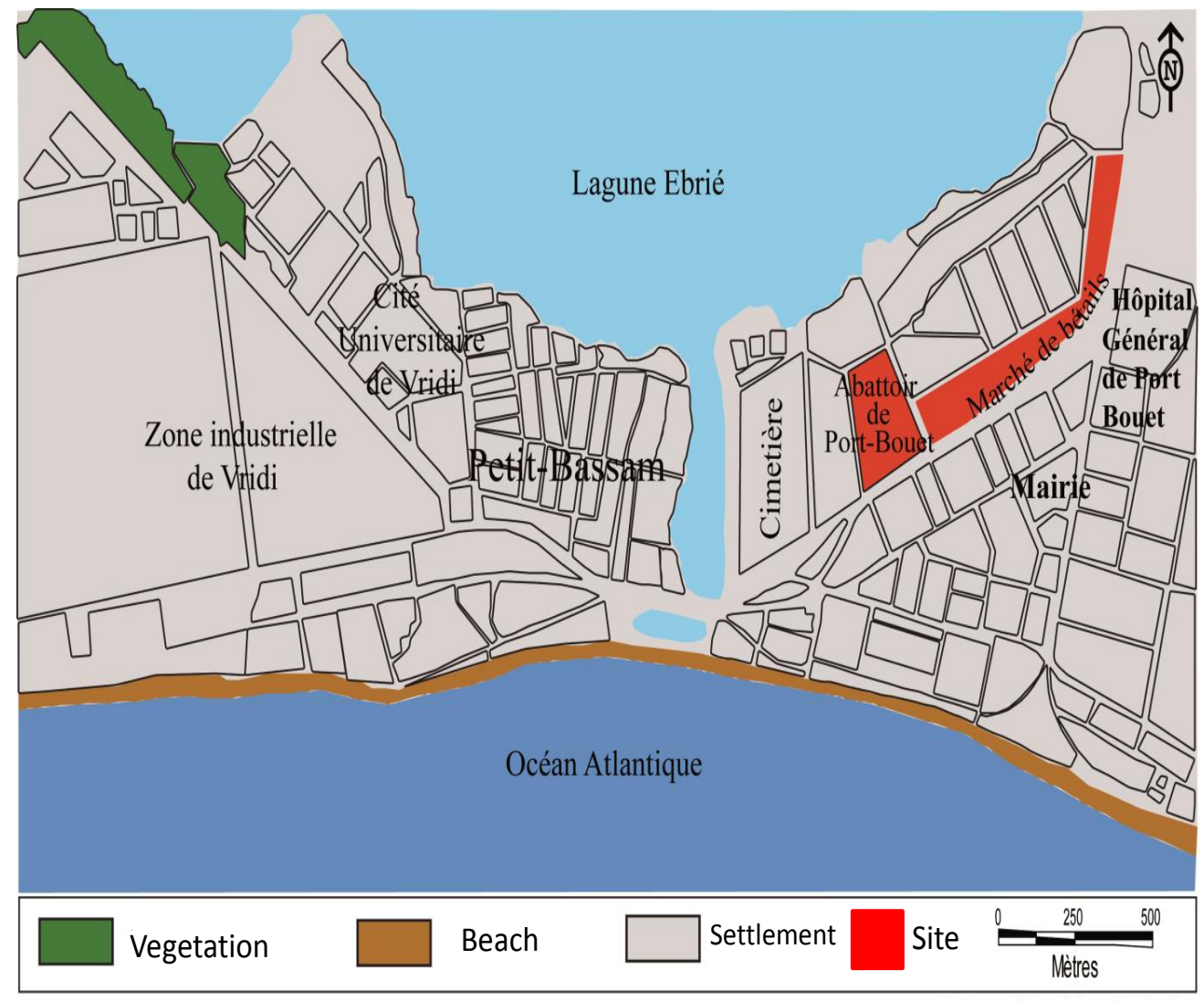

Source:Google Map, 2014

Infographie: Adou K. Arsène

Figure 1: Map of the study area showing the Port-Bouët abattoir. 


\section{RESULTS}

\section{Prevalence of $C E$ in the slaughtered cattle}

The prevalence of $\mathrm{CE}$ at the slaughterhouse in Port-Bouët was determined thanks to the different data relating to the animals slaughtered between 2008 and 2015 (1 023431 cattle slaughtered) and the number of $\mathrm{CE}$ cases identified (i.e. the number of cattle identified as having this parasitosis, $\mathrm{N}=16396$ cases), resulting in an overall prevalence of $1.6 \%$. In addition, this data made it possible to evaluate the prevalence of each inspection year (Table 1).

The highest value was recorded in 2008 (3.39\%). In addition to this value, it was noticed that between 2012 and 2015, the values obtained increased over the years i.e. 2012 (1.07\%), 2013 (1.31\%), 2014 (1.73\%) and $2015(2.34 \%)$. However, the 2010 and 2011 cases for the disease were $1.01 \%$ and
$1.5 \%$ respectively. The minimum prevalence was obtained in 2009 (0.82\%) (Figure 2). Comparing the prevalence to the years of organ isolation showed that there was a statistically significant difference $(P<0.05)$ in prevalence with the different years of examination.

\section{Prevalence with respect to the type of organ examined}

Data on the various organs isolated revealed that of the organs isolated, 16396 were diagnosed positive for echinococcosis. The identified cases were all from the kidneys of the slaughtered cattle where the hydatid cysts were found (Figure 2). The infection prevalence of the kidney was $100 \%$. Regarding other organs inspected (tongue, liver, lung, heart, and spleen); no case of hydatid cyst was observed (Figure 3).

Table I. Cystic echinococcosis in isolated organs at the Port-Bouët abattoir.

\begin{tabular}{ccccc}
\hline Years & Number slaughtered & Number examined & Number of cases & Frequency $(\boldsymbol{\%})$ \\
\hline 2008 & 91661 & 29464 & 3111 & 3.39 \\
2009 & 110175 & 16480 & 899 & 0.82 \\
2010 & 105623 & 21079 & 1070 & 1.01 \\
2011 & 84671 & 14275 & 1266 & 1.50 \\
2012 & 164948 & 24473 & 1762 & 1.07 \\
2013 & 164919 & 27458 & 2158 & 1.31 \\
2014 & 153407 & 27558 & 2660 & 1.73 \\
2015 & 148027 & 30461 & 3470 & 2.34 \\
\hline 8 years & 1023431 & 191248 & 16396 & 1.60 \\
\hline
\end{tabular}

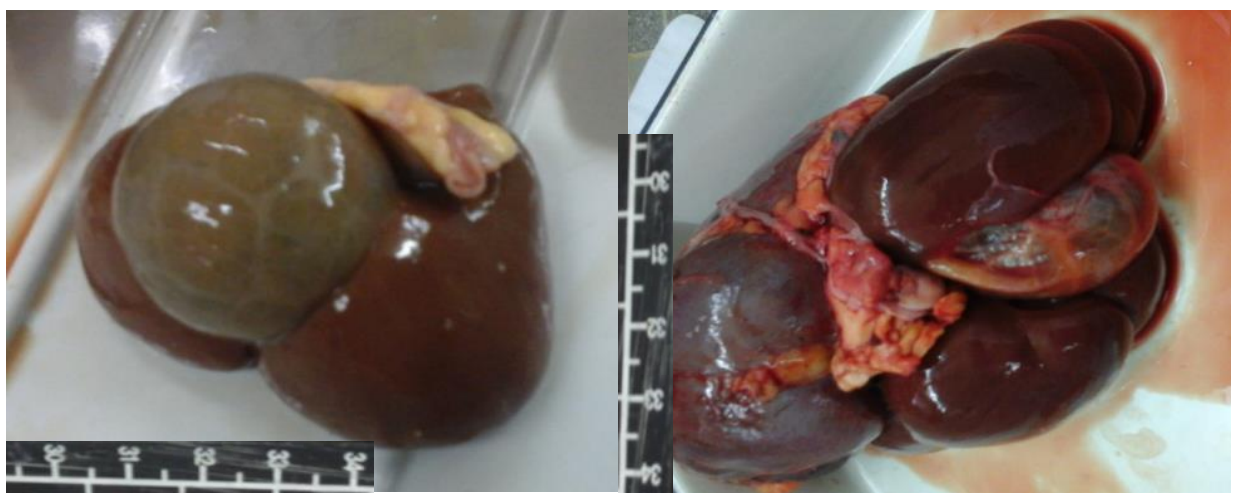

Figure 2: Bovine liver showing Echinococcus cyst. 


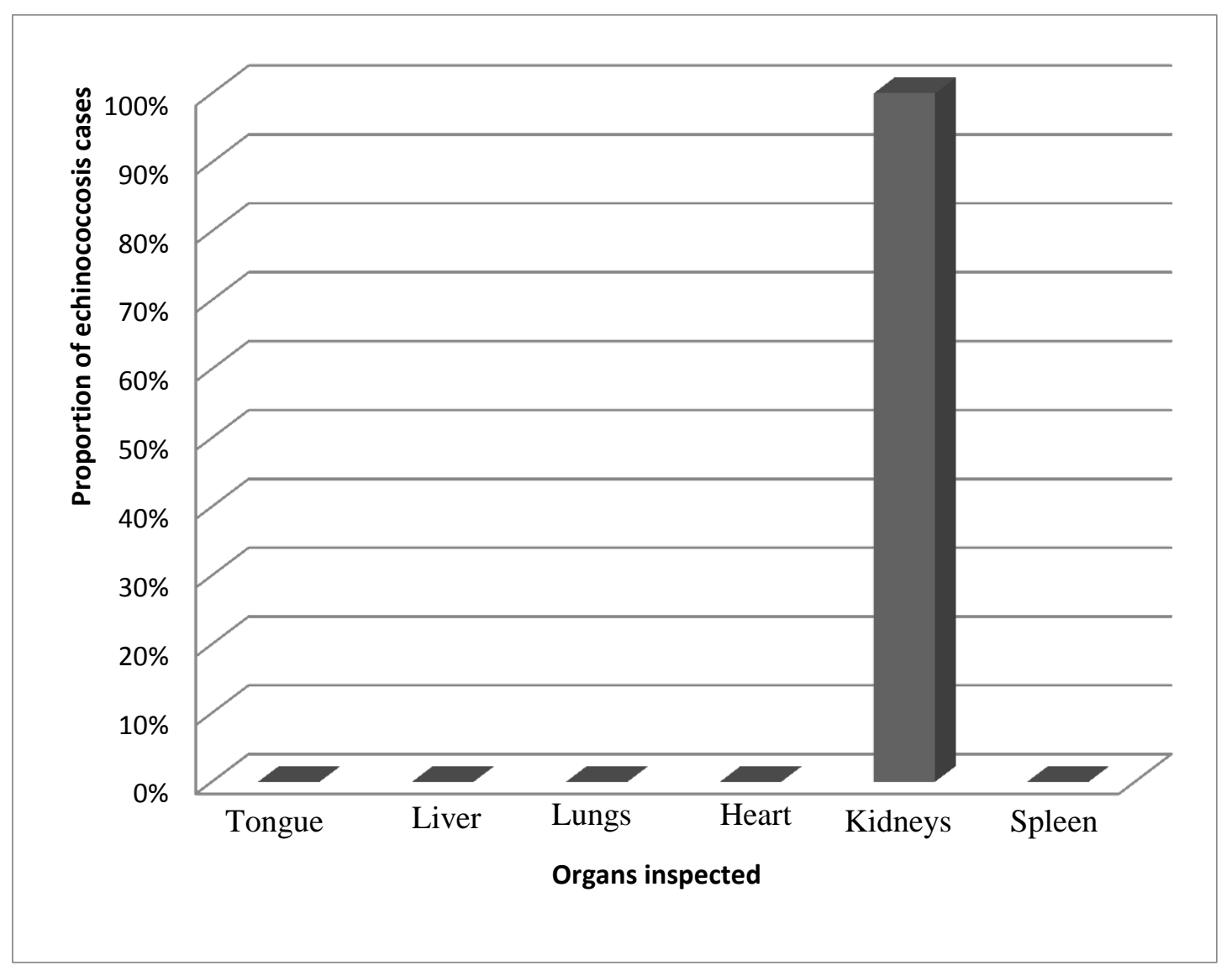

Figure 3: Evaluation of the different organs inspected for echinococcosis.

\section{DISCUSSION}

The prevalence of bovine echinococcosis in isolated organs at the PortBouët abattoir over the period of eight years from 2008 to 2015 was $1.6 \%$ (16396 out of 1 023431 cattle slaughtered). This value can be justified by the fact that echinococcosis was not regularly encountered at this slaughter house by the veterinary services. The presence of this zoonosis in Côte d'Ivoire is as a result of importation of cattle from neighboring countries like Burkina Faso and Mali. The present prevalence confirms the low prevalence of $\mathrm{CE}$ in most sub-Saharan countries along the broad Sahel Zone (Eckert et al., 2001; Pierre, 2013).

This study is preliminary in Côte d'Ivoire and concerned only one abattoir (the abattoir in Port-Bouët); which could be the reason for the low prevalence value obtained. In other parts of the region particularly the countries of North Africa, the prevalence of bovine $\mathrm{CE}$ is much higher than that obtained in Ivory Coast. In Morocco and Egypt, studies revealed 22.98\% (Azlaf and Dakkak, 2006) and $6.4 \%$ (Harridy et al., 2006) respectively. This disease also prevails in Middle East countries, particularly Iran and Iraq with prevalence rates of $22.9 \%$ and $10.9 \%$ respectively (Saeed et al., 2000) and were well above the prevalence of echinococcosis obtained in this study. A study in Kenya (30\%) recorded a high prevalence of $\mathrm{CE}$ (Njoroge et al., 2002). Note that most of these countries are endemic to this parasitosis. In addition, the present study revealed that only the kidneys were carriers of the different hydatid cysts discovered. It has been 
mentioned in many studies (Khuroo, 2002; Eckert and Deplazes, 2004) that kidneys are among the organs with infection rates much lower than that of the liver and lungs (organ that favor this parasite). The preference of this organ (the kidney) as compared to others by the parasite may be due to several factors (possibly physical and chemical factors) that favored its development (Ehsan et al., 2017). Similarly, the high occurrence in the kidney could be due to the less sensitive para-clinical method used as compared to a more sensitive test like PCR which could have led to the identification of more cases and in other organs as compared to that obtained in the present study. However, histological and molecular examinations if performed will give the exact prevalence of this parasite in Côte d'Ivoire. Indeed, host specificity of the larval form is visible by comparing the different strains within the species (E. granulosus in our case). Each strain has a preferential intermediate host (from which it gets its name) but can also develop in other hosts, but with a lower outcome (Ripoche, 2009).

\section{Conclusion}

The present study at the Port-Bouët abattoir revealed that echinococcosis was present in Côte d'Ivoire. Far from being regularly encountered by veterinary inspection, this parasitosis still has a significant prevalence $(1.6 \%)$ in the present preliminary study on cattle. In view of the potential dangers of the disease, this prevalence must be considered with great attention. The different hydatid cysts recorded during health inspections were found only in the kidneys of slaughtered cattle. Because of this, if the inspections were thoroughly carried out, a new strain of Echinococcus granulosus would have been found, which is responsible for most of the cases of echinococcosis outbreaks in Africa. More in-depth studies i.e. molecular studies of cysts will permit the high sensitivity detection of the prevailing strains in this slaughter house. Other ruminants (goat and sheep) together with humans need to be studied for infections with echinococcosis in order to present the exact situation of echinococcosis in Côte d'Ivoire. The results obtained in the present study serves as baseline data which marks the starting point of a broad research process for the acquisition of much knowledge about echinococcosis of Côte d'Ivoire.

\section{COMPETING INTERESTS}

The authors declare that they have no competing interests.

\section{AUTHORS' CONTRIBUTIONS}

GLYA, BJMV and SSL conceived the idea for the work and wrote the proposal; YBC and SSL assisted in the technical aspect of this study and in editing the manuscript. Both parties gave final approval to the manuscript.

\section{ACKNOWLEDGEMENTS}

Authors are very grateful to the veterinary nurses of the Port-Bouët for their collaboration during inspections.

\section{REFERENCES}

Azlaf R, Dakkak A. 2006. Epidemiological study of the cystic echinococcosis in Morocco. Vet. Parasitol., 137: 83-93. DOI: 10.1016/j.vetpar.2006.01.003.

Battelli G, Mantovani A, Seimenis A. 2002. Cystic echinococcosis and the Mediterranean Region: a long-lasting association. Parassitologia, 44: 43-57.

Bizuwork A, Kebede N, Tibat T, Tilahun G, Kassa T. 2012. Occurrences and financial significance of bovine cystic echinococcosis in Southern Wollo, Northeastern Ethiopia. J. Vet. Med. Anim. Hlth., 5: 51-56. DOI: 10.5897/JVMAH12.072.

Eckert J, Deplazes P. 2004. Biological, epidemiological, and clinical aspects of Echinococcosis, a zoonosis of increasing concern. Clin. Microbiol. Rev., 17. 107135. DOI: $10.1128 / C M R .17 .1 .107-$ 135.2004.

Eckert J, Deplazes P, Craig PS, Gemmel MA, Gottstein B, Heath D, Jenkins DJ, Kamya M, Lightowlers M. 2001. Echinococcosis in animals: clinical 
aspects, diagnosis and treatment. WHO/OIE Manual on Echinococcosis in Humans and Animals. 72-79.

Ehsan M, Akhter N, Bhutto B, Arijo A, Ali Gadahi J. 2017. Prevalence and genotypic characterization of bovine Echinococcus granulosus isolates by using cytochrome oxidase 1 (Co1) gene in Hyderabad, Pakistan. Vet. Parasitol., 239: 80-85.

DOI: 10.1016/j.vetpar.2017.04.006.

Harridy FM, Ibrahim BB, Elshazli AM, Awad SE, Sultan DM, El-Sherbini GT, Morsy TA. 2006. Hydatidosis granulosus in Egyptian slaughtered animals in the years 2000-2005. J. Egyptian Soc. Parasitol., 36: 1087-100.

Honsset R, Mignon B, Loson B. 2004. Données récentes sur une zoonose d'actualité: l'échinococccose alvéolaire due à Echinococcus multilocularis. Annales Med Vét., 148: 153-167.

Khuroo MS. 2002. Hydatid disease: current status and recent advances. Annals Saudi Med., 22. 56-64.

Marisk L, Jacob W, Paolo P, Katrien, Katinka VH. 2008. Les zoonoses: les maladies transmissibles de l'animal à l'homme. Agrodok., 46: 79.

Majorowski MM, Carabin H, Kilani M. Bensalah A. 2005. Echinococcosis in Tunisia: a cost analysis. Transactions Royal Soc. Trop. Med. Hyg., 99: 268278.

Njoroge EM., Mbithi PM, Gathuma JM, Wachira TM, Gathura PB, Magambo JK, Zeyle E. 2002. A study of cystic echinococcosis in slaughter animals in three selected areas of northern Turkana,
Kenya. Vet. Parasitol., 104: 85-91. https://doi.org/10.1016/S03044017(01)00614-8.

Ripoche M. 2009. La lutte contre l'hydatidose en Sardaigne, Thèse pour obtenir le grade de Docteur Vétérinaire, Université Paul-Sabatier de Toulouse, France.108.

Saeed I, Kapel C, Saida LA, Willingham L, Nansen P. 2000. Epidemiology of Echinococcus granulosus in Arbil province, northern Iraq, 1990-1998. J. Helminthol., 74: 83-88.

Savey M, Dufour B. 2004. Diversité des zoonoses. Définition et conséquence pour la surveillance et la lutte. Epidémiologie et Santé Animale. 46 : 116.

Thompson RCA, Lymbery AJ. 1999. Echinococcus and Hydatid Disease. CAB International: Wallingford, Oxon (UK) ; 477.

WHO. 2006. La lutte contre les zoonoses négligées. Réseau international des autorités de sécurité sanitaire des aliments. Note d'information INFOSAN $\mathrm{N}^{\circ}$ 1/2006-Zoonoses.

Yao-Acapovi GL, Mavoungou JF, Sevidzem SL. 2018. Tick population on large and small ruminant species in the Port-Bouët cattle market in Abidjan, Ivory Coast. Livestock Res Rural Development, 30: 111.

Yang YR, Rosenzvit MC, Zhang LH, Zhang JZ, Macmanus DP. 2005. Molecular study of Echinococcus in west-central China. Parasitol., 131: 547-555. DOI: 10.1017/S0031182005007973. 